\title{
The Importance of Some Possible Somatic and Environmental Risk Factors for the Development of Migraine
}

\author{
Han Le ${ }^{a}$, Peer Tfelt-Hansen ${ }^{\mathrm{a}}$, Axel Skytthe ${ }^{\mathrm{b}}$, Kirsten Ohm Kyvik ${ }^{\mathrm{c}, ~ d}$, \\ Jes Olesen ${ }^{\mathrm{a}, \mathrm{e}}$
}

\begin{abstract}
Background: The study of risk factors of migraine is important, not least because migraine prevalence seems to increase. The knowledge of risk factors remains limited, however, despite years of research. The objective was to evaluate some possible somatic and environmental risk factors for the development of migraine.
\end{abstract}

Methods: The Danish Twin Omnibus 1994 and 2002 were questionnaire surveys investigating somatic disorders, lifestyle factors and socioeconomic factors. Both studies used the same validated questions to diagnose migraine. The study population included twin individuals born between 1953 and 1976 who in 1994 reported never to have had migraine. We compared the groups with and without a specific disorder or environmental factor in 1994 with regard to their migraine status in 2002.

Results: This study comprised 13,498 subjects (6,513 men and 6,985 women). The 8 -year risk of developing migraine was significantly increased in subjects who already had low back pain (odds ratio (OR) $=1.3 ; 95 \% \mathrm{CI}=1.2-1.4)$. Environmental factors associated with an increased risk of development of migraine were low education $(\mathrm{OR}=$ $1.3 ; 95 \% \mathrm{CI}=1.1-1.5)$, heavy physical workload $(\mathrm{OR}=1.1 ; 95 \% \mathrm{CI}$ $=1.0-1.2)$, heavy physical recreational activity $(\mathrm{OR}=1.2 ; 95 \% \mathrm{CI}$ $=1.0-1.3)$ and body mass index $(\mathrm{BMI})<18.5(\mathrm{OR}=1.3 ; 95 \% \mathrm{CI}=$ 1.1 - 1.6). Subjects with weekly or more frequent alcohol consumption had a lower risk of developing migraine compared to subjects with less frequent or no consumption of alcohol $(\mathrm{OR}=0.6 ; 95 \% \mathrm{CI}$ $=0.6-0.7)$.

Manuscript accepted for publication May 18, 2015

aThe Danish Headache Center, Department of Neurology, University of Copenhagen, Glostrup Hospital, Glostrup, Denmark

${ }^{\mathrm{b}}$ The Danish Twin Registry, Epidemiology, Institute of Public Health, University of Southern Denmark, Odense, Denmark

'Institute of Regional Health Services Research, University of Southern Denmark, Odense, Denmark

dOdense Patient data Explorative Network (OPEN), Odense University Hospital, Odense, Denmark

${ }^{\mathrm{e}}$ Corresponding Author: Jes Olesen, Danish Headache Center, Department of Neurology, Glostrup Hospital, Glostrup DK-2600, Denmark.

Email: jes.olesen@regionh.dk

doi: http://dx.doi.org/10.14740/jnr336w
Conclusions: This large-scale longitudinal population-based study showed that the risk of development of self-reported migraine was increased in subjects with low back pain, low education, heavy physical workload and heavy physical recreational activity, and decreased in those with frequent alcohol consumption.

Keywords: Migraine; Possible risk factors; Low back pain; Low education; Underweight

\section{Introduction}

The study of risk factors of migraine is important in order to prevent migraine in the general population. Despite several large studies published recently [1-3], our understanding of the risk factors of migraine remains limited. Several twin studies have shown that the heritability of the migraine phenotype is approximately $40-60 \%$ [4-9]. The rest should, therefore, be accounted for by environmental factors. Some factors may affect migraine in a positive and others in a negative way. Our previous cross-sectional studies showed that low level of schooling and education, unemployment or smoking were associated with an increased risk of migraine, whereas an inverse association was seen between physical exercise and migraine [10]. Migraine was co-morbid with several somatic diseases including low back pain, arthritis, thyroid diseases, asthma and allergies, suggesting that such disorders may play a role in the development of migraine [11]. In order to identify factors or diseases that may be potential risk factors and not consequences of migraine, longitudinal studies are required. So far only few longitudinal studies have investigated risk factors of migraine [1, 12-14].

The Danish Twin Omnibus 1994 and 2002 were questionnaire studies among almost 30,000 and 35,000 twin individuals respectively. They included questions regarding migraine, several somatic disorders, lifestyle factors and socioeconomic factors. Both studies used the same validated questions to diagnose migraine as well as its subtypes migraine with aura (MA) and migraine without aura (MO) $[15,16]$. In this paper the twin status is disregarded and the material is presented as a random sample from the Danish population, which is acceptable since these twins are representative of the whole Danish population with regard to migraine [17] as well as several 


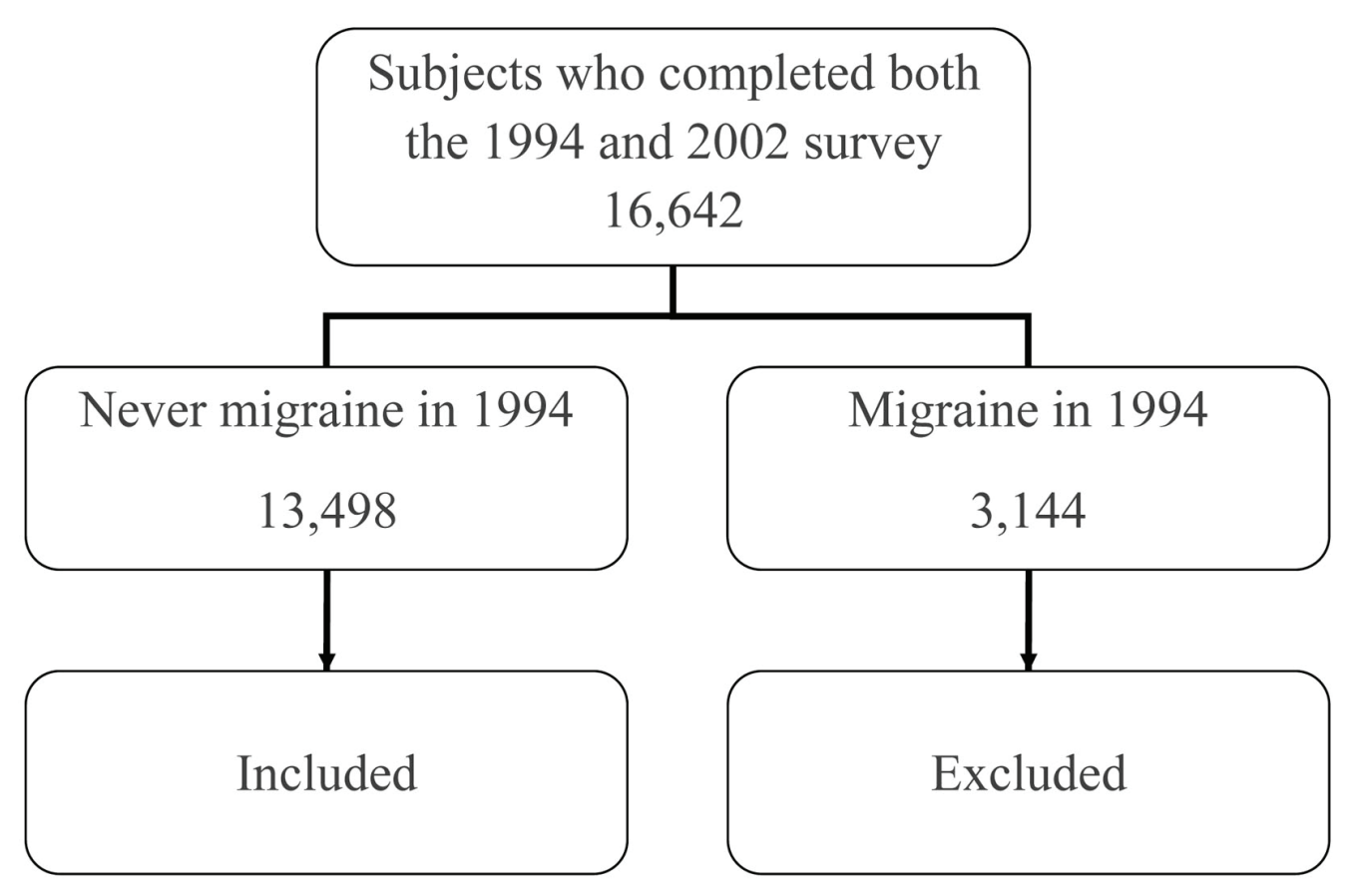

Figure 1. Flowchart of the study population aged $18-41$.

other phenotypes, e.g., diabetes [18, 19], asthma [20] and mortality [21]. Subjects who reported never to have had migraine in 1994 (baseline) were followed up in 2002. The aim of the study was to evaluate the possible contribution of some somatic and environmental factors for the development of migraine in an adult population, stratified accordingly to MA and MO as well as sex.

\section{Material and Methods}

\section{Study population}

The Danish Twin Registry is the oldest and most complete national twin registry in the world [15]. The ascertainment of twins has been done in a variety of ways. The Danish Civil Registration System, which has registered all persons living in Denmark since April 2, 1968, was used as the primary source for enrollment of the twins in the present study $[15,16]$. Twins born between 1953 and 1982 were identified via the mother assuming that a woman giving birth to more than one child within three consecutive days had twins [22].

Self-reported migraine was identified based on the following questions. 1) Have you ever had migraine? 2) Have you ever had visual disturbances that lasted from 5 to $60 \mathrm{~min}$ and were succeeded by a headache?

Subjects answered "yes" to question 1 were classified as having migraine. MA was defined as subjects answering "yes" to both questions, and MO was defined as subjects answering "yes" to question 1 and "no" to question 2. Subjects answering "no" to question 1 were considered healthy. Validation of the screening questions showed that it is possible to identify $76 \%$ of all subjects with migraine, $85 \%$ of all with MA and $72 \%$ of all with MO. A detailed description of the validation of screening questions has been published elsewhere [11].

Our study population included twin individuals born between 1953 and 1976 (both inclusive) who had answered both migraine questions in 1994 and 2002. Those who reported having or having had migraine in 1994 were excluded. We used data from the 1994 survey to establish the exposure status. The outcome was based on self-reported migraine in 2002.

\section{The twin surveys}

The Twin Omnibus 1994 and 2002 contained besides the migraine questions also questions about several somatic diseases and environmental factors. In 1994 information about various diseases was based solely on self-report, whereas in 2002 most diagnoses on patients were self-reported physician-made diagnoses. This difference in the questions resulted in big difference in the prevalence of some diagnoses. We included only diagnoses with greater than $70 \%$ concordance in the two surveys. We therefore included only epilepsy (89\%), asthma $(86 \%)$ and low back pain $(74 \%)$ in the analysis. The environmental factors in 1994 included educational level, physical workload, physical recreational activity, smoking status, alcohol consumption, weight and height. Body mass index (BMI) was calculated from the height and weight measurements and categorized according to the World Health Organization's BMI 
Table 1. Associations Between Asthma, Epilepsy and Low Back Pain and the 8-Year Risk of Development of Migraine in a Danish Population Aged 18 - 41

\begin{tabular}{llll} 
Disease & Migraine prevalence in \% (n) & MA prevalence in \% (n) & MO prevalence in \% (n) \\
\hline Asthma & $15.0(1,127)$ & $6.2(42)$ & $9.9(70)$ \\
Without asthma & $13.8(1,735)$ & $4.9(555)$ & $9.8(1,180)$ \\
OR $(95 \%$ CI) & $1.10(0.89-1.35)$ & $1.29(0.92-1.79)$ & $1.01(0.78-1.30)$ \\
Epilepsy & $14.7(29)$ & $4.5(8)$ & $11.1(21)$ \\
Without epilepsy & $13.9(1,841)$ & $5.0(595)$ & $9.8(1,246)$ \\
OR (95\% CI) & $1.07(0.72-1.58)$ & $0.91(0.45-1.87)$ & $1.14(0.73-1.80)$ \\
Low back pain & $15.0(1,257)$ & $5.6(423)$ & $10.5(834)$ \\
Without low back pain & $12.0(611)$ & $3.9(181)$ & $8.8(430)$ \\
OR (95\% CI) & $1.29(1.17-1.44)$ & $1.47(1.23-1.76)$ & $1.22(1.08-1.38)$ \\
\hline
\end{tabular}

classification [23].

\section{Definition of risk factors}

We considered a specific disease (asthma, epilepsy and low back pain in 1994) as a possible risk factor for migraine by comparing the prevalence of self-reported migraine in 2002 in the groups with the specific disease to the prevalence in the group without the specific disease. For the environmental factors we compared the risk of reporting migraine for low education (higher education for less than 3 years) vs. high education (higher education for more than 3 years); high physical workload (work including walk, lift and heavy physical demands) vs. low physical workload (mainly seated or standing); heavy physical recreational activity $(2 \mathrm{~h}$ or more of heavy physical exercise per week) vs. low physical recreational activity (no or light physical exercise as well as heavy physical exercise less than $2 \mathrm{~h}$ per week); current smokers or former smokers vs. non-smokers; regular alcohol consumption (weekly or more frequent) vs. occasional alcohol consumption (less than weekly or no alcohol consumption); underweight, overweight and obese subjects vs. normal weight subjects [23].

\section{Statistical analyses}

Univariate analyses were used to investigate the association between migraine and each of the risk factors. We compared the groups with and without a specific disease or environmental factor in 1994 with regard to their migraine status in 2002. We used a generalized estimating equation model to adjust for relatedness. The results were given as odds ratios (ORs) with 95\% confidence intervals (CI). Missing data were excluded from the analyses. All analyses were stratified by migraine subtype and sex. Data analysis was performed with PASW Statistics Version 18.0 by SPSS Inc.

\section{Results}

A flowchart of the study population is presented in Figure 1. The 13,498 subjects aged 18 - 41 (6,513 men and 6,985 wom- en) did not report having migraine ever in 1994. The mean age of this population was $29 \pm 7$ years (SD). The risk of developing migraine and its subtypes in 2002 dependent on having one of the three specific diseases evaluated or environmental factors in 1994 is summarized in Table 1 and 2.

We found that the 8-year risk of developing migraine was significantly increased in subjects who in 1994 had low back pain. The risk of developing MA as well as the risk of MO was also significantly increased in subjects with low back pain. Stratification by sex showed that low back pain was associated with the development of migraine both in men $(\mathrm{OR}=$ $1.3 ; 95 \% \mathrm{CI}=1.1-1.6)$ and in women $(\mathrm{OR}=1.3 ; 95 \% \mathrm{CI}=$ 1.1 - 1.4). Significant association with the development of MA and MO was also seen in men whereas the association was only significant for MA in women (data not shown). There was no association with migraine observed for asthma $(\mathrm{OR}=1.1$; $95 \% \mathrm{CI}=0.9-1.4)$ or epilepsy $(\mathrm{OR}=1.1 ; 95 \% \mathrm{CI}=0.7-1.6)$ (Table 1).

Environmental factors associated with an increased risk of development of migraine were low education, heavy physical workload, heavy physical recreational activity and underweight. The first three mentioned factors were associated with MO, whereas the risk of developing MA was only significantly increased in underweight subjects. Subjects with alcohol consumption weekly or more had a lower risk of developing migraine as well as MA and MO compared to subjects with occasional or no consumption of alcohol. Stratification by sex also showed this effect of regular alcohol consumption in men for both subtypes (MA: OR $=0.6$; $95 \% \mathrm{CI}=0.4-0.8, \mathrm{MO}: \mathrm{OR}=0.7 ; 95 \% \mathrm{CI}=0.5-0.9)$ but not in women. Heavy physical workload was associated with the development of $\mathrm{MO}$ but not MA in men $(\mathrm{OR}=1.4 ; 95 \%$ $\mathrm{CI}=1.2-1.7)$ as well as in women $(\mathrm{OR}=1.2 ; 95 \% \mathrm{CI}=$ $1.0-1.4)$.

\section{Discussion}

This 8-year longitudinal study comprised a large representative, non-selective sample $(n=13,498)$ of the Danish population. The main findings indicated that the development of self-reported migraine was associated with low back pain and several environmental factors. The migraine subtypes MA and 
Table 2. Associations Between Environmental Factors and the 8-Year Risk of Development of Migraine in a Danish Population Aged $18-41$

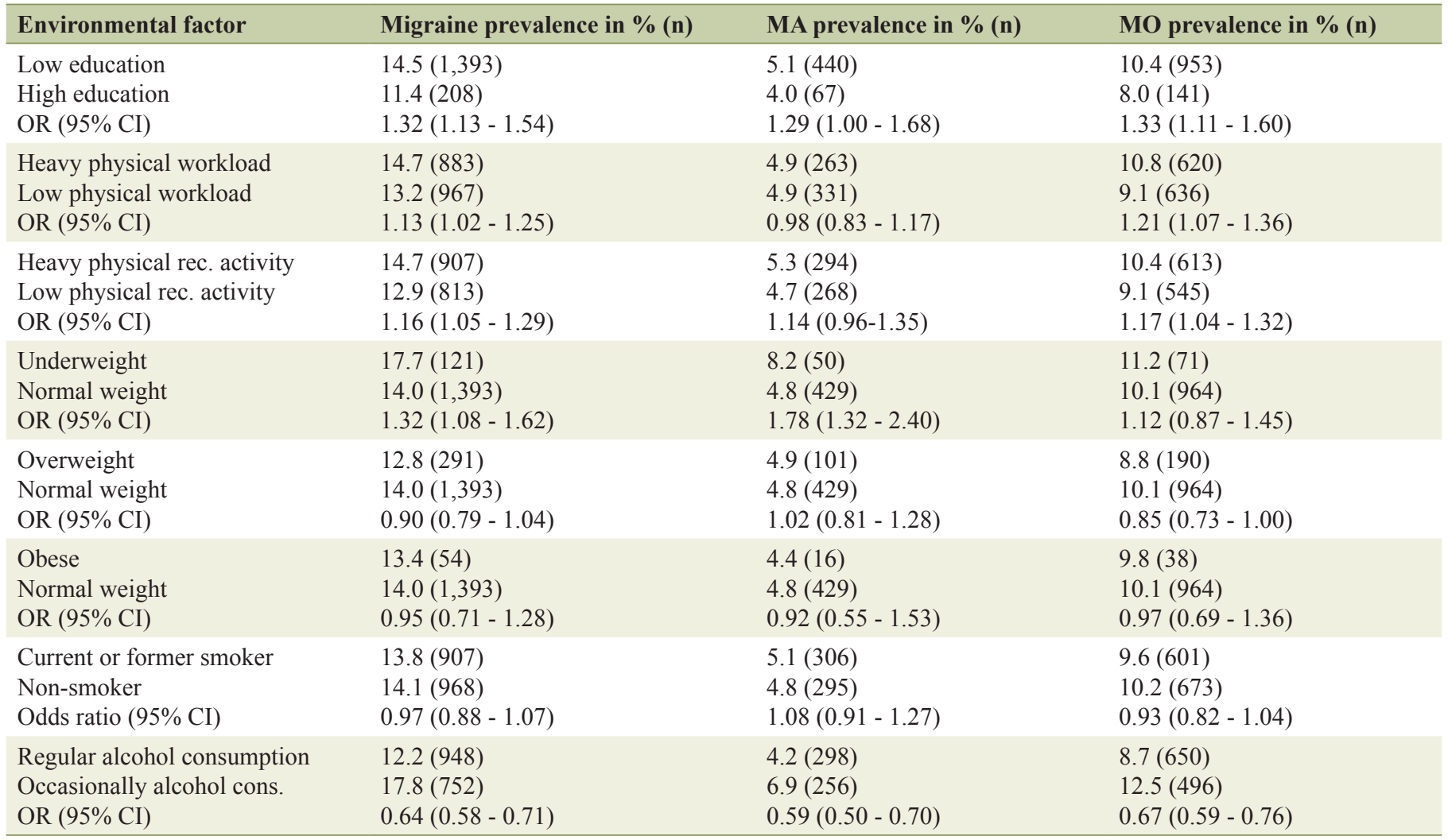

MO were associated with different environmental factors, and so were men and women.

\section{The three evaluated disorders as risk factors}

In cross-sectional studies we have previously shown that migraine is co-morbid with low back pain, asthma, epilepsy and several other somatic disorders [11]. Of the three diagnoses that could be evaluated in the present study, only low back pain seems, however, to be associated with the development of migraine and its subtypes. Our results agree with a Canadian study that showed an increased risk of migraine development with pre-existing back problems, but the investigators did not segregate the sexes [13]. It is likely that conditions involving musculoskeletal pain increase the risk of developing migraine by inappropriate muscle tension or compensatory structural adjustments of the neck or upper back muscles. A very small American study $(\mathrm{n}=46)$ [24] reported that $46 \%(95 \% \mathrm{CI}=19$ $73 \%)(6 / 13)$ of women developed MO following the onset of low back pain but as shown by the wide $95 \%$ CI, this is likely the same as the $18 \%$ migraine prevalence in women in the US. No significant difference was seen in men, since only $8 \%$ of men (2/26) developed MO [24]. Our study demonstrated that low back pain is associated with the development of migraine in both men and women. The same was true for the male subjects in both MA and MO whereas in women this was only the case for MA. Asthma and epilepsy did not increase the risk of developing migraine in the present study. Asthma has previously been reported as not being a risk factor for the development of migraine [13]. A family study of epilepsy did find the incidence risk of migraine to be 2.4 times higher in subjects with epilepsy than without epilepsy [25]. To our knowledge, no longitudinal population-based study on migraine and epilepsy has been published.

\section{Environmental factors}

Previous cross-sectional studies have shown that social factors such as education $[10,26,27]$ and socioeconomic status [26, 28 ] are associated with migraine. It has been suggested that this may be due to downward social drift, but the present data suggest that low education and heavy physical workload may induce migraine. A cohort study of 7793 -year-old children followed for 23 years showed that verbal IQ in childhood was associated with the development of migraine and the chance of school success was $9.5 \%$ less for students later diagnosed with migraine [29]. It is possible that factors associated with low education leading to low income may explain these otherwise alarming results. Thus, an unhealthy lifestyle, stress or poor education may be causative factors. Heavy physical workload predisposed to MA in women, but not in men, in one study [10], whereas heavy physical recreational activity is associated 
with a decreased risk of migraine in most $[1,2,10]$ but not all [3] studies.

Exertion of the musculoskeletal apparatus leading to muscle tensions may thus cause the experience of migraine. $\mathrm{Mi}$ graineurs are likely to avoid physical exertion in order to prevent migraine attacks. Our finding could explain the association found previously between migraine and physical inactivity [2, $5,10]$. Low back pain was more common among subjects with physically demanding work but not with heavy physical activity during leisure time [30]. We found that underweight subjects had a higher risk of developing migraine compared to normal weight subjects, but we could not confirm previous findings of an increased risk in obese persons. Smoking did not increase the risk of developing migraine. This is in keeping with another study showing that smoking during mid-adolescence did not increase the risk of developing frequent headache including migraine in adulthood [5, 31]. However, the risk of new migraine cases has been reported to be higher among current smokers in a cohort study with up to 15-year follow-up period [14]. That study used a slightly younger sample than ours, and it differentiated between former smokers and current smokers. A separate analysis of current smokers at baseline in our study did not show any association with subsequent development of migraine (data not shown). Regular alcohol consumption in 1994 decreased the risk of developing migraine and its subtypes. Migraine sufferers are known to be prone to develop headache and migraine after alcohol consumption [32, 33]. We believe that subjects susceptible to migraine could have experienced non-migraine headaches after alcohol prior to their onset of migraine. This could lead to avoidance behavior towards alcohol in migraine-prone individuals.

\section{Methodological consideration}

This study was a population-based twin study with a large sample size $(\mathrm{n}=13,498)$. The subjects were studied twice, 8 years apart. This sample size allowed for the analysis of risk for development of combined migraine, MA and MO for both three somatic disorders and several environmental factors. A limitation was that information on somatic disorders was obtained in 1994 by self-report and in 2002 by self-reported physician-made diagnoses. Thus only asthma, epilepsy and low back pain, which all had a concordance between the two surveys of $>70 \%$, could be used. An additional limitation of this study is that it did not include evaluations of psychiatric disorders.

\section{Conclusions}

During a large 8-year longitudinal study, patients with low back pain developed more MA and MO than subjects without this disorder. This was not the case for epilepsy or asthma. Low education and underweight were associated with an increase risk of migraine, and regular alcohol consumption was associated with a decreased risk of MA and MO.

These results should be taken into account when migraine prevention in the general population is considered.

\section{References}

1. Varkey E, Hagen K, Zwart JA, Linde M. Physical activity and headache: results from the Nord-Trondelag Health Study (HUNT). Cephalalgia. 2008;28(12):1292-1297.

2. Molarius A, Tegelberg A, Ohrvik J. Socio-economic factors, lifestyle, and headache disorders - a populationbased study in Sweden. Headache. 2008;48(10):14261437.

3. Winter AC, Hoffmann W, Meisinger C, Evers S, Vennemann M, Pfaffenrath V, Fendrich K, et al. Association between lifestyle factors and headache. J Headache Pain. 2011;12(2):147-155.

4. Gervil M, Ulrich V, Kaprio J, Olesen J, Russell MB. The relative role of genetic and environmental factors in migraine without aura. Neurology. 1999;53(5):995-999.

5. Honkasalo ML, Kaprio J, Winter T, Heikkila K, Sillanpaa M, Koskenvuo M. Migraine and concomitant symptoms among 8167 adult twin pairs. Headache. 1995;35(2):7078.

6. Larsson B, Bille B, Pedersen NL. Genetic influence in headaches: a Swedish twin study. Headache. 1995;35(9):513-519.

7. Mulder EJ, Van Baal C, Gaist D, Kallela M, Kaprio J, Svensson DA, Nyholt DR, et al. Genetic and environmental influences on migraine: a twin study across six countries. Twin Res. 2003;6(5):422-431.

8. Ulrich V, Gervil M, Kyvik KO, Olesen J, Russell MB. The inheritance of migraine with aura estimated by means of structural equation modelling. J Med Genet. 1999;36(3):225-227.

9. Ziegler DK, Hur YM, Bouchard TJ, Jr., Hassanein RS, Barter R. Migraine in twins raised together and apart. Headache. 1998;38(6):417-422.

10. Le H, Tfelt-Hansen P, Skytthe A, Kyvik KO, Olesen J. Association between migraine, lifestyle and socioeconomic factors: a population-based cross-sectional study. J Headache Pain. 2011;12(2):157-172.

11. Le H, Tfelt-Hansen P, Russell MB, Skytthe A, Kyvik $\mathrm{KO}$, Olesen J. Co-morbidity of migraine with somatic disease in a large population-based study. Cephalalgia. 2011;31(1):43-64.

12. Breslau N, Davis GC, Andreski P. Migraine, psychiatric disorders, and suicide attempts: an epidemiologic study of young adults. Psychiatry Res. 1991;37(1):11-23.

13. Gilmour H, Wilkins $\mathrm{K}$. Migraine. Health Rep. 2001;12(2):23-40.

14. Hozawa A, Houston T, Steffes MW, Widome R, Williams $\mathrm{OD}$, Iribarren $\mathrm{C}$, Pletcher $\mathrm{MJ}$, et al. The association of cigarette smoking with self-reported disease before middle age: the Coronary Artery Risk Development in Young Adults (CARDIA) study. Prev Med. 2006;42(3):193-199.

15. Skytthe A, Kyvik K, Holm NV, Vaupel JW, Christensen $\mathrm{K}$. The Danish Twin Registry: 127 birth cohorts of twins. Twin Res. 2002;5(5):352-357.

16. Skytthe A, Kyvik K, Bathum L, Holm N, Vaupel JW, Christensen K. The Danish Twin Registry in the new millennium. Twin Res Hum Genet. 2006;9(6):763-771. 
17. Ulrich V, Gervil M, Fenger K, Olesen J, Russell MB. The prevalence and characteristics of migraine in twins from the general population. Headache. 1999;39(3):173-180.

18. Kyvik KO, Green A, Beck-Nielsen H. Concordance rates of insulin dependent diabetes mellitus: a population based study of young Danish twins. BMJ. 1995;311(7010):913917.

19. Poulsen P, Kyvik KO, Vaag A, Beck-Nielsen H. Heritability of type II (non-insulin-dependent) diabetes mellitus and abnormal glucose tolerance--a population-based twin study. Diabetologia. 1999;42(2):139-145.

20. Skadhauge LR, Christensen K, Kyvik KO, Sigsgaard T. Genetic and environmental influence on asthma: a population-based study of 11,688 Danish twin pairs. Eur Respir J. 1999;13(1):8-14.

21. Christensen K, Vaupel JW, Holm NV, Yashin AI. Mortality among twins after age 6: fetal origins hypothesis versus twin method. BMJ. 1995;310(6977):432-436.

22. Kyvik KO, Green A, Beck-Nielsen H. The new Danish Twin Register: establishment and analysis of twinning rates. Int J Epidemiol. 1995;24(3):589-596.

23. Obesity: preventing and managing the global epidemic. Report of a WHO consultation. World Health Organ Tech Rep Ser. 2000;894:i-xii, 1-253.

24. Duckro PN, Schultz KT, Chibnall JT. Migraine as a sequela to chronic low back pain. Headache. 1994;34(5):279281.

25. Ottman R, Lipton RB. Comorbidity of migraine and epilepsy. Neurology. 1994;44(11):2105-2110.
26. Hagen K, Vatten L, Stovner LJ, Zwart JA, Krokstad S, Bovim G. Low socio-economic status is associated with increased risk of frequent headache: a prospective study of 22718 adults in Norway. Cephalalgia. 2002;22(8):672679.

27. Stang P, Sternfeld B, Sidney S. Migraine headache in a prepaid health plan: ascertainment, demographics, physiological, and behavioral factors. Headache. 1996;36(2):69-76.

28. Lipton RB, Stewart WF, Diamond S, Diamond ML, Reed M. Prevalence and burden of migraine in the United States: data from the American Migraine Study II. Headache. 2001;41(7):646-657.

29. Waldie KE, Hausmann M, Milne BJ, Poulton R. Migraine and cognitive function: a life-course study. Neurology. 2002;59(6):904-908.

30. Bjorck-van Dijken C, Fjellman-Wiklund A, Hildingsson C. Low back pain, lifestyle factors and physical activity: a population based-study. J Rehabil Med. 2008;40(10):864869.

31. Waldie KE, McGee R, Reeder AI, Poulton R. Associations between frequent headaches, persistent smoking, and attempts to quit. Headache. 2008;48(4):545-552.

32. Panconesi A. Alcohol and migraine: trigger factor, consumption, mechanisms. A review. J Headache Pain. 2008;9(1):19-27.

33. Rasmussen BK. Migraine and tension-type headache in a general population: precipitating factors, female hormones, sleep pattern and relation to lifestyle. Pain. 1993;53(1):65-72. 